\title{
A Relevância do Estágio Supervisionado no Âmbito da Formação de Licenciados em Geografia
}

\section{La Relevancia del Estagio Supervisado en el Ámbito de la Formación de Maestros en Geografía}

\section{Resumo:}

O presente artigo parte de uma reflexão teórica acerca do processo de escolarização, para posteriormente discutir aspectos relativos ao Estágio Supervisionado na formação dos Licenciados em Geografia, entendido enquanto momento crucial de aproximação do graduando com a multiplicidade da sala de aula. A reflexão se pauta em referenciais bibliográficos, mas também em experiências pessoais no contexto de orientações e supervisões dos Estágios Supervisionados nos anos de 2015 e 2016, no âmbito da Universidade Estadual do Oeste do Paraná (UNIOESTE), Campus Marechal Cândido Rondon. Neste trabalho estão presentes apontamentos e debates sobre as principais questões que envolvem a prática do estagiário junto aos alunos na experiência do estágio.

\section{Resumen:}

Este artículo es una reflexión teórica sobre el proceso de la escolarización, para discutir con mayor detalle aspectos de los estagios supervisados en la formación de los graduados en Geografía, entendida como un momento crucial de la aproximación del estudiante con la multiplicidad de la clase. La reflexión es guiada en las referencias bibliográficas, sino también en las experiencias personales en el contexto de la orientación y supervisión de lo estagio supervisado en los años 2015 y 2016, dentro de la Universidade Estadual do Oeste do Paraná (UNIOESTE), Campus Marechal Cândido Rondon. En el presente trabajo son las notas actuales y debates sobre las principales cuestiones relacionadas con la práctica del alumno con los estudiantes durante la experiencia de lo estagio.

* MSc. em Geografia pela UNIOESTE/M.C.R. Docente do Curso de Geografia da UNIOESTE/M.C.R. Integrante do Grupo de pesquisa "ENGEO - Ensino e práticas de Geografia" e do Grupo de pesquisa "Cultura, Fronteira e Desenvolvimento Regional".

\section{Palavras-chave:}

Estágio Supervisionado, Formação Docente, Escolarização

\section{Palabras clave:}

Estagio Supervisado, Formación de Maestros, Escolarización 


\section{INTRODUÇÃO}

discussão presente neste artigo surge a partir de experiências vivenciadas enquanto orientadora e supervisora no âmbito dos Estágios Supervisionados em Geografia, na Universidade Estadual do Oeste do Paraná, durante os anos de 2015 e 2016. Para tal, foram aplicados questionários qualitativos aos acadêmicos que se dispuseram a contribuir com suas percepções sobre o Estágio Supervisionado em Geografia, bem como considerações individuais com base nas experiências vivenciadas junto aos estagiários e as escolas. Portanto, são apresentadas questões a partir de um contexto pontual, mas que constantemente permeiam os diálogos entre docentes e discentes na Universidade. Apenas algumas das questões respondidas pelos acadêmicos foram trazidas ao contexto do presente artigo, visando analisar os aspectos principais, uma vez que, sendo realizados individualmente, os estágios apresentam várias particularidades inerentes ao próprio estagiário.

Além disso, foi construída uma breve reflexão teórica sobre o processo de escolarização, destacando a constituição e as finalidades da escola, enquanto instituição formal de ensino. A formação de professores, bem como a relevância do Estágio Supervisionado como parte integrante desta, também foram debatidos brevemente neste artigo. Com isso, pretende-se formular argumentos que demonstrem o quão importante é o momento do estágio na formação dos alunos, percebendo também as principais dificuldades neste processo, bem como as preocupações que comumente surgem entre os acadêmicos.

Esta primeira reflexão teórica apresentada por meio deste artigo se pauta nas discussões comumente estabelecidas em sala de aula, quando os acadêmicos estudam e refletem acerca da constituição da educação formal e das escolas enquanto instituições responsáveis pela concretização desta. Ainda, sobre o papel docente na formação de um pensamento crítico por parte dos alunos do Ensino Básico, os quais não devem ser vistos como meros produtos de um sistema vigente, mas como sujeitos sociais, parte integrante da construção dos conhecimentos historicamente acumulados.

Neste sentido, é importante que os acadêmicos, antes de efetivamente entrarem em sala de aula no âmbito dos estágios, possam reconhecer a complexidade daquilo que estarão fazendo. Se não compreenderem o papel social da escola e a importância do professor, certamente farão um estágio descontextualizado. Para tanto, conhecimentos teóricos são desenvolvidos nas aulas das diversas disciplinas do currículo acadêmico da Licenciatura em Geografia (Políticas da Educação, Didática, Práticas de Ensino, etc.). Essas discussões perpassam temáticas fundamentais, optando-se, neste artigo, por trazer apenas um curto embasamento antes de efetivamente explanar sobre os estágios, visando mostrar que a prática não é um processo descontextualizado, mas que tem uma função social importante, não apenas como etapa de formação do acadêmico.

\section{A ESCOLARIZAÇÃo E A RELEVÂNCIA DO ESTÁGIO SUPERVISIONADO NOS CURSOS DE LICENCIATURA}

De antemão, torna-se relevante destacar que a escola, enquanto instituição social, não é um elemento naturalizável, uma vez que, no formato como a concebemos atualmente, foi constituída em um contexto histórico específico, atrelada ao capitalismo industrial (ABREU, 2012). Suas finalidades naquele momento visavam uma separação dos conteúdos divinos (responsabilidade das instituições religiosas) dos conhecimentos racionais que, portanto, se constituiriam enquanto responsabilidades da escola, a qual teria a função de formação do cidadão apto ao contexto social emergente, o que em termos objetivos significa que os indivíduos seriam formados para suprir às necessidades da mão-de-obra fabril emergente na ocasião.

A escola, neste sentido, desde seu surgimento enquanto instituição formal de ensino, é permeada pelos discursos hegemônicos, ideológicos, responsáveis pela disseminação do pensamento das classes dominantes na sociedade. Abreu (2012), buscando referencial teórico em Sérgio Paulo Rouanet, analisa que a escola é o espaço em que se concentra uma significativa carga ideológica, mas também é o ambiente no qual coexiste a possiblidade do contradiscurso, e justamente daí deriva a complexidade de uma análise acerca da escola, tendo-se em vista a atuação dos múltiplos agentes envolvidos no processo de escolarização.

Deste modo, entende-se que no ambiente escolar são disseminados conhecimentos com forte carga ideológica, no sentido de formação de um pensamento único, visando a constituição de uma sociedade apta a atender às necessidades de uma classe dominante, a qual detém os meios de produção. Assim, em termos mais 
amplos e generalistas, a função da escola seria a de formação de pessoal apto ao mercado de trabalho e, para tal, não seriam necessários conhecimentos reflexivos, questionadores e críticos.

Neste sentido, Vlach (2016) afirma que "o saber ler, escrever e realizar as quatro operações da aritmética tornaram-se indispensáveis para o desenvolvimento tecnológico de que essa revolução econômica é o marco inconteste". Ou seja, para suprir às exigências do capitalismo industrial emergente, não eram necessários, da parte dos trabalhadores, mais do que alguns conhecimentos simples, os quais seriam responsabilidade do sistema escolar reproduzir.

Para além da referida caracterização primária da escola, esta também torna-se como o espaço de disseminação de um contradiscurso, justamente com base na diversidade de pensamentos daqueles sujeitos que a constituem, mesmo que estes também estejam inseridos na mesma sociedade capitalista moderna, pois se fazem necessárias essas abordagens na escola atual, tendo-se em vista as próprias contradições inerentes ao capitalismo.

Assim, pautada em anseios sociais de maior igualdade e uma percepção do caráter ideológico dos conhecimentos escolares, se intensifica um pensamento libertador, pautado na criticidade e na negação. Essa forma de construção do conhecimento, por vezes atrelada ao materialismo histórico e dialético, é considerada subversiva e perigosa, uma vez que desmistifica e desmascara os conhecimentos imputados pelas classes dominantes no contexto escolar. No entanto, entende-se que a escola tem a função, no contexto contemporâneo, também de abrigar ideias e indivíduos pensantes, os quais são a base fundamental da constituição do indivíduo em sujeito social, apto ao exercício de função cidadã.

Cabe destacar que, neste processo de constituição de uma escolarização com conteúdos apropriados do contradiscurso, o professor possui um papel relevante, uma vez que é um dos sujeitos responsáveis pela discussão crítica dos conhecimentos, diferentemente do conceito de professor em um processo de escolarização pautado no discurso hegemônico, no qual o professor é um mero transmissor de conhecimentos pré-estabelecidos e ditados como corretos pelo currículo formal. Quanto à percepção que se tem historicamente do professor, Abreu (2012, p. 13) analisa que:

Um agente fundamental do processo ensino-aprendizagem escolar é o professor, que "ensina", que domina e reproduz um conjunto de conteúdos formalizados em um currículo escolar e que, historicamente, é mal remunerado, subordinado aos interesses e valores hegemônicos. Uma visão simplista, mas ainda dominante, que coloca o professor como transmissor do conhecimento, reduzindo a produção do conhecimento a uma função mecânica e descontextualizada.

A visão socialmente padronizada do professor enquanto indivíduo que domina e reproduz um conjunto de conhecimentos estabelecidos por um grupo hegemônico através do livro didático, como recurso único no processo de ensino/aprendizagem, é uma concepção constituída a partir de um discurso que pretende legitimar e conformar a sociedade em relação ao papel do professor. Este discurso é impactado pela possiblidade de atuação de um professor que se constitui sujeito social, e que compreende que o processo de escolarização não é neutro e naturalizável. Quando o professor adquire consciência do poder do contradiscurso que é possível no ambiente escolar, ele supera a visão de sua atuação como transmissor de conteúdos, e percebe que o conhecimento é construído, cotidianamente, na interação entre todos os agentes que constituem o contexto escolar, desde a esfera governamental até a familiar.

Quanto ao professor de Geografia, Abreu (2012, p. 22) analisa que este

[...] deverá permitir/estimular o aluno na sua capacidade de pesquisar, raciocinar, relacionar, argumentar, criar e aprender, superando a prática da cartilha e do exercício simples de memorização, sem negligenciar a importância dos conteúdos científicos sistematizados e sua apreensão como possiblidade emancipatória. Trata-se de assumir o papel de formação do cidadão para a sociedade, preparando-o para ser sujeito, questionador e transformador de sua realidade.

A Geografia, entendida como um dos campos do conhecimento relativo às humanidades, foi por muito tempo, especialmente no âmbito brasileiro, considerada também uma disciplina a qual deveria se ter cautela, segundo o ideário dominante. $\mathrm{O}$ contexto em que esse sentimento foi com maior intensidade percebido é o período da Ditadura Civil-Militar no Brasil, isso porque a Geografia "é a disciplina que pode explicar às crianças e adolescentes os processos que levam a compreender porque a coexistência, contraditória e complementar, das lógicas territorial e das redes, agravou as desigualdades existentes" (VLACH, 2016, p. 09), mas não apenas isso, a Geografia, a partir de seu arcabouço teórico e conceitual, pode promover discussões que rompam com a lógica e os pensamentos emitidos historicamente pelas classes hegemônicas e que perpetuam o sistema capitalista enquanto um modelo que supostamente atende à todos, e 
que organiza o espaço geográfico segundo preceitos de desenvolvimento. Esse descortiçamento é um contradiscurso que gera desconfortos aos que detém, em tese, o poder sobre os conhecimentos escolares que devem, ou não, serem transmitidos.

Os espaços de formação de professores, no contexto contemporâneo, são locais profícuos de discussão acerca do processo de escolarização, uma vez que as licenciaturas possibilitam ao graduando contatos com discussões teóricas que aprofundam as várias problemáticas relativas ao contexto escolar, bem como a atuação e reflexão prática em sala de aula, por meio dos Estágios Supervisionados, os quais são etapas obrigatórias na formação do professor das várias disciplinas que compõem o currículo escolar. É neste momento da formação docente que o estagiário, salvo exceções dos que já lecionam durante a graduação, terá contato com a sala de aula, ambiente de aplicação dos conhecimentos teóricos e práticos desenvolvidos no âmbito da formação acadêmica. É também o momento de perceber como os discursos e contradiscursos estão presentes e influenciam as práticas no cotidiano escolar.

\section{PERCEPÇÕES ACERCA DO ESTÁGIO SU- PERVISIONADO EM GEOGRAFIA}

O Estágio Supervisionado em Geografia é um momento crucial na formação dos graduandos no âmbito das licenciaturas, constituindo-se no momento de utilização dos recursos e metodologias estudados teoricamente, mas também da aplicação dos conhecimentos acumulados no decorrer do curso. Sendo um momento de tamanha relevância, torna-se do mesmo modo um período de realização, mas também de tensão por parte de alguns acadêmicos, uma vez que para a ampla maioria, este é o primeiro contato com a realidade escolar de forma direta. As preocupações dos acadêmicos derivam da possiblidade de uma experiência inédita, mas por vezes se amparam também na falta de preparo, seja ele teórico, metodológico ou mesmo emocional/psicológico.

Cabe ressaltar que o Estágio Supervisionado em Geografia, no âmbito da Universidade Estadual do Oeste do Paraná, Campus Marechal Cândido Rondon, é atualmente desenvolvido em três etapas. O "Estágio Supervisionado I (Prática de Ensino I)" é desenvolvido como disciplina aos acadêmicos do $2^{\circ}$ ano do curso, e não conta com o estágio obrigatório nas escolas. Consistindo no momento em que os acadêmicos entram em contato com as legislações, regulamentos e documentos relativos ao estágio. Além disso, a disciplina se divide em duas partes, uma com 30 horas teó- ricas e outra com 38 horas práticas, momento este em que os graduandos desenvolvem práticas e metodologias que poderão ser aplicadas em sala de aula no contexto dos estágios obrigatórios.

Já o "Estágio Supervisionado II (Prática de Ensino II)" é desenvolvido no $3^{\circ}$ ano do curso, e é neste momento que os alunos terão a possiblidade de estar em sala de aula no contexto do Ensino Fundamental ( $6^{\circ}$ à $9^{\circ}$ ano). No momento atual, os acadêmicos devem ministrar 12 regências em sala, após terem observado o espaço escolar e as aulas da turma em que farão o estágio. Da mesma forma ocorre no "Estágio Supervisionado III (Prática de Ensino III)", havendo apenas a mudança em relação ao perfil das salas em que os estagiários estão ministrando suas aulas, desta vez no Ensino Médio ( $1^{\circ}$ à $3^{\circ}$ ano). Portanto, entende-se que o Estágio Supervisionado em Geografia, no contexto apresentado, segue uma ordem lógica e crescente de aperfeiçoamento do acadêmico, em um patamar de acréscimo de complexidade, mostrando uma real evolução do estagiário quando finalizadas as etapas previstas.

Durante todo período de realização dos estágios, o acadêmico possui o acompanhamento de um professor orientador e supervisor, cuja função é de:

[...] a) orientar, acompanhar, supervisionar e avaliar as atividades do estagiário sob sua responsabilidade; b) elaborar, propor e encaminhar ao coordenador de Estágio o plano de acompanhamento de estágio; c) orientar a elaboração e aprovar o plano de atividade do estagiário; d) responsabilizar-se, juntamente com o estagiário, pela entrega de todos os documentos exigidos no Regulamento de Estágio; e) apresentar ao coordenador de Estágio relatórios, conforme definido no Regulamento de Estágio do Curso; f) propor ao coordenador de Estágio o desligamento de acadêmico do campo de estágio, quando se fizer necessário; g) cumprir e fazer cumprir a legislação, normas e Convênios ou Termos de Cooperação referentes ao Estágio (CONSELHO..., 2011, p. 10).

Assim, entende-se que o professor orientador e supervisor de Estágio será o responsável pelas etapas burocráticas em relação à realização dos estágios, atuando conjuntamente à Coordenação de Estágio Supervisionado e, quando necessário, com a Coordenação do curso de Licenciatura em Geografia. Todos os agentes envolvidos no processo do Estágio Supervisionado possuem funções bem definidas, visando garantir que o estagiário obtenha êxito nessa importante etapa de sua formação, bem como promovendo um processo integrativo entre a escola e a Universidade. Além das atribuições relacionadas acima, quando eventualmente o professor orientador for também Supervisor do Estágio, torna-se necessário ainda que cumpra o papel de acompanhar 
os alunos em sala de aula por um período de aulas pré-estabelecidas, visando auxiliar no que preciso for, bem como avaliar a atuação docente do estagiário.

São atribuições do acadêmico estagiário neste processo:

I - elaborar planejamento (Plano de Aula e Texto Paradidático) para o estágio no ensino fundamental e médio, que deve ser submetido à aprovação dos docentes supervisores e do docente de Prática de Ensino correspondente, antes da execução do referido planejamento; II - identificar os locais de desenvolvimento do estágio, por meio de carta de apresentação fornecida pela Coordenação do Estágio; III - solicitar, a cada aula observada ou ministrada, a assinatura do docente da turma (cooperador) na Ficha do Cronograma; IV - apresentar, ao final de cada estágio (ensino fundamental e médio) um relatório geral a respeito das atividades desenvolvidas (contendo os Formulários I, II, III, IV, V, VI e VII anexos), de acordo com o que for estabelecido pelo docente de Prática de Ensino correspondente, acompanhado dos documentos comprobatórios necessários; V - realizar as atividades previstas para o estágio (CONSELHO..., 2011, p. 11)

Assim, percebe-se que a função e atuação dos acadêmicos estagiários não se restringe às regências em sala de aula, mas perpassa certames burocráticos e preparatórios, que visam dar legitimidade ao processo de estágio corrente. Existem, para tanto, documentos que devem ser preenchidos e assinados, bem como um relatório final que deverá ser elaborado, garantindo que o estágio tenha sido efetivamente realizado, e que todos os passos previstos, pelo menos em tese, tenham sido registrados no relatório final. Portanto, o momento do Estágio Supervisionado em Geografia, é de grande importância para o estagiário, e envolve várias dimensões de organização, inclusive por parte das próprias escolas que acolherão os estagiários.

É relevante, em relação ao estágio, romper com a visão tradicionalmente constituída que visa dicotomizar a teoria e a prática, conforme demonstrado por Pimenta; Lima (2005/2006, p. 06) quando analisam que:

O estágio sempre foi identificado como a parte prática dos cur-
sos de formação de profissionais em geral, em contraposição
à teoria. Não é raro ouvir-se dos alunos que concluem seus
cursos se referirem a estes como "teóricos", que a profissão se
aprende "na prática", que certos professores e disciplinas são
por demais "teóricos". Que "na prática a teoria é outra".

Afirmativas como estas são comumente encontradas nos cursos de licenciatura, e refletem um problema mais complexo do que a simples reprodução de uma fala comum. Abreu (2012) analisa que até recentemente os cursos de licenciatura no Brasil estavam vinculados à uma formação técnica do professor, e que este modelo de formação apresentava algumas limitações e problemas, especialmente em relação à separação entre os conhecimentos teóricos e práticos (conteúdos acadêmicos e disciplinas de prática, didática, etc.), consequentemente gerando uma sensação de que a teoria de alguma forma se sobreporia à prática, bem como uma visão de que a prática seria um mero processo de aplicação dos conhecimentos teóricos. Aliado à este cenário, seria construída uma visão de que "para ser um bom professor basta o domínio da área do conhecimento específico que se vai ensinar" (ABREU, 2012, p. 22).

Essas concepções se perpetuaram no decorrer do tempo, e continuam gerando discursos dicotomizados em relação à teoria e à prática, constituindo um arcabouço teórico que, por vezes, não sendo relacionado ao viés da prática. Neste sentido, segundo Abreu (2012), a Lei de Diretrizes e Bases da Educação Nacional (LDB), aprovada em 1996, estabelece que a formação docente não é a mera aplicação de conhecimentos teóricos, de forma prática, no ambiente escolar. Mas sim, um processo amplo de criação e reflexão. Portanto, diferentemente do que a escolarização em períodos de conservadorismo, tal qual foi o contexto da Ditadura Civil-Militar brasileira, a prática docente no contexto contemporâneo deveria ser livre de amarras e discursos ideológicos, mas sim promotora de um processo formativo em sala de aula pautado na criação do conhecimento, ou seja, o aluno enquanto agente na elaboração das hipóteses, enquanto sujeito pesquisador, e que constrói um conhecimento refletido e autônomo, embora mediado pelo conhecimento e intervenção docente.

O Estágio Supervisionado em Geografia não é o momento em que o estagiário observará o professor regente da turma e buscará neste um modelo pronto de atuação, ou pelo menos se espera que não faça isso, mas buscar-se-á no contexto do estágio um espaço de exercício docente, no qual o estagiário poderá trabalhar de forma prática com os conhecimentos que construiu no decorrer do processo formativo, aliando teoria e prática, mas também conhecendo um pouco sobre as dificuldades do processo de construção dos conhecimentos. É, portanto, um momento profícuo de experimentação, certamente que amparada pelos professores regentes das escolas, bem como pelo professor orientador e supervisor da Universidade. Neste espaço e momento o acadêmico estagiário começa a perceber quais as metodologias e os recursos que podem ser utilizados, em conformidade com cada realidade de sala de aula.

É no contexto do Estágio Supervisionado em Geografia que o acadêmico perceberá a diversidade e complexidade de uma sala de aula. É comum que aconteçam situ- 
ações como uma extensiva preparação teórica do estagiário para entrar em sala de aula, bem como o desenvolvimento e intenção de utilização de recursos didáticos com a finalidade de incremento qualitativo nas aulas, mas ao chegar no ambiente escolar, o estagiário se deparar com uma realidade que limita suas possiblidades, dentro do planejado, de atuação docente. A falta de motivação por parte dos alunos, bem como o desinteresse em relação à disciplina, atrelando-se à isso a carência de recursos didáticos em boa parte das escolas públicas, acabam se tornando empecilhos ao estagiário durante sua experiência em sala. Ainda assim, são problemas que envolvem questões mais amplas, como políticas e sociais, construindo a realidade escolar, em relação à qual o estagiário estará desenvolvendo suas funções.

Tendo-se como premissa a análise das percepções de alguns estagiários (alguns já formados atualmente) em relação aos Estágios Supervisionados em Geografia, buscou-se a elaboração e aplicação de pesquisa qualitativa com questões pré-determinadas. E, para tanto, foram enviados questionários específicos aos alunos que estagiaram no ano de 2015, tanto no âmbito do Ensino Fundamental ( $3^{\circ}$ ano do curso), quanto no Ensino Médio ( $4^{\circ}$ ano do curso), mas apenas para aqueles que foram orientados e supervisionados pela autora do presente artigo, visando compreender de perto as percepções dos alunos, podendo assim traçar algumas reflexões.

Cabe destacar que o curso de Licenciatura em Geografia da Universidade Estadual do Oeste do Paraná, Campus Marechal Cândido Rondon, sofre, como vários outros cursos de licenciatura no Brasil, um processo de redução quantitativa em relação aos acadêmicos que se mantém ativos até o término do curso, ou seja, há um índice significativo de evasão do curso no decorrer do mesmo. O que acaba, em alguns anos, gerando turmas bastante reduzidas. Ainda que não seja um padrão imutável, porque esporadicamente se constituem turmas que chegam volumosas em termos quantitativos ao término da graduação. Nove estagiários responderam os questionários, e algumas das principais ideias obtidas a partir deste material seguem abaixo:

\section{- Como foi sua relação com os alunos?}

Os estagiários foram unanimes em afirmar que ao longo do estágio tiveram um bom relacionamento com os alunos das salas em que atuaram. Dos alunos que responderam o questionário, todos realizaram seus estágios em turmas do Ensino Médio, ou seja, já haviam tido outra experiência em ano anterior no âmbito do Ensino Fundamental. Esse é um detalhe importante, pois espera-se que os estagiários evoluam em relação ao relacionamento com a turma de um ano para o outro. Apesar disso, em algumas ocasiões essa evolução não se mostra tão nítida, justamente pela diversidade das salas de aula. O método de relacionamento com uma turma, não será exatamente igual ao método de relacionamento que funcionará em outras turmas. Assim, a questão domínio de turma acaba sendo bastante subjetiva, porque envolve a identificação dos alunos com o professor estagiário.

- Quais foram suas maiores dificuldades no Estágio?

Os estagiários responderam que uma das maiores dificuldades reside na dificuldade de organização do tempo, uma vez que a falta de experiência acaba prejudicando neste sentido, atrelando-se a isso o fato de que vários acadêmicos trabalham do período diurno, e estudam no período noturno. Então acabam vendo que o excesso de afazeres prejudica, de alguma forma, sua atuação no estágio. Além disso, citaram que o deslocamento é outro problema que causa um desgaste e prejudica a realização do estágio. Alguns acadêmicos residem em municípios vizinhos, menores, e cursam a graduação em Marechal Cândido Rondon. Os estágios também são realizados no referido município, então os acadêmicos devem deslocar-se com a finalidade de conseguir cumprir as regências obrigatórias no estágio. Esse fato acaba se constituindo como um problema, sob a perspectiva dos estagiários, pois o deslocamento demanda tempo e esforço, o que supostamente afeta o desenvolvimento dos estágios.

Outro fator destacado pelos estagiários em relação às suas principais dificuldades se refere a conseguir delimitar os conteúdos indicados pelos professores regentes das escolas no período das doze aulas que deverão ministrar. Por não terem experiência neste sentido, sentem-se preocupados com a forma pela qual deverão efetuar o recorte do conteúdo, entendendo-se que não podem ministrar o conteúdo de forma superficial, mas também devem cumprir com o tema dentro do prazo estipulado. Levando em consideração que alguns acadêmicos nunca estiveram em sala de aula antes como professores, e não têm esse domínio em relação ao tempo, acabam ficando temerosos diante da possiblidade de não conseguirem abarcar todos os conteúdos, ou de passarem muito rapidamente aquilo que precisam ensinar. Essa acaba sendo uma das problemáticas mais frequentes em relação aos estágios.

- Qual foi seu maior aprendizado no Estágio?

Os acadêmicos responderam que aprenderam que o Estágio Supervisionado em Geografia é um momento de superação, e que eles não devem desistir quando surgem as adversidades. Segundo eles, o estágio é um momento de desenvolvimento, no qual eles aprenderam muito, e que puderam perceber em quais áreas ainda precisavam melhorar. Um 
estagiário respondeu que o estágio o possibilitou o contato com a necessidade de uma abordagem interdisciplinar, visando relacionar os conhecimentos geográficos com os demais campos do conhecimento, buscando com isso a criticidade e a reflexão. Com isso, entende-se que o Estágio Supervisionado em Geografia é um período de amadurecimento intelectual, mas também das próprias concepções que se tinha até aquele momento.

Nota-se que há um padrão entre as respostas dos estagiários quanto às questões propostas qualitativamente, embora existam particularidades, como a condição de residir distante dos locais onde os estágios são desenvolvidos. No geral, as preocupações costumam ser as mesmas, expostas e discutidas nas várias reuniões efetuadas durante todo processo do estágio (orientações, elaboração de planos de aula e textos paradidáticos, regências e relatório final), as quais se concentram na expectativa de como será o contato com os alunos, qual o retorno do professor regente da turma quanto ao papel do estagiário e como serão efetuadas as avaliações por parte dos professores orientadores/supervisores. Outras preocupações mais pontuais também perpassam as inquietações dos estagiários, como a ideal conduta em sala de aula, como se deve chamar a atenção dos alunos, questões burocráticas.

Em um viés abrangente, pode-se dizer que em sua ampla maioria, os estagiários superam suas próprias expectativas e saem realizados da experiência, salvo exceções, claro. Boa parte deles demonstra o quão gratificante foi a experiência no contexto da realização do relatório final, quando estes têm a oportunidade de traçar agradecimentos e dedicatórias, bem como discorrer sobre suas percepções acerca do estágio. Assim, conclui-se que o Estágio Supervisionado em Geografia é um dos momentos mais aguardados pelos acadêmicos, gerando dúvidas e ansiedades, mas que faz uma imensa diferença no contexto da formação dos Licenciados em Geografia, os quais têm a possiblidade de vivenciar uma experiência acompanhada pelo prof. Coordenador do Estágio Supervisionado, contando com a orientação e supervisão de um prof. da Universidade e ainda sob atenção do prof. regente da turma. Desta forma, é um ambiente de construção de conhecimentos e amadurecimento, preparando o acadêmico para a futura profissão que este escolheu, à docência.

\section{CONSIDERAÇÕES FINAIS}

O Estágio Supervisionado é um momento crucial nos cursos de Licenciatura, ocasião em que boa parte dos acadêmicos têm seu primeiro contato com a sala de aula, seu futuro ambiente de trabalho. Alguns acadêmicos já tiveram experiências anteriores, especialmente quando há, na Universidade, extensões como o Programa Institucional de Bolsa de Iniciação à Docência (PIBID) que proporciona aos estudantes a oportunidade de desenvolver atividades junto às escolas, inclusive ministrando aulas em sua área específica. No entanto, essa não é a realidade de todos os graduandos. Para grande maioria, o Estágio Supervisionado é um o primeiro encontro efetivo com os alunos, com a realidade escolar.

O Estágio Supervisionado reflete apenas em parte a realidade da escolarização, pois o estagiário não é o responsável pela turma, portanto, havendo algumas limitações em sua atuação. Essas limitações podem ser maiores ou menores dependendo do professor regente que acompanha os estágios. Alguns fornecem autonomia grande ao estagiário, para que este escolha os métodos e conteúdos que ministrará. Outros, no entanto, limitam a atuação do estagiário, tanto em termos do conteúdo, quanto aos métodos adotados. Nota-se que a presença do estagiário, por vezes, pode representar uma desestabilização na rotina do professor regente, o qual imagina que não terá condições de seguir os métodos adotados pelo estagiário. No entanto, isso ocorre em uma pequena minoria dos casos. Em geral, os professores regentes são receptivos e grandes aliados na formação dos acadêmicos.

A parcialidade do estágio reside também na não criação de vínculo empregatício ou duradouro em relação à escola, constituindo-se, portanto, em apenas um momento específico na formação do acadêmico. Assim, a realidade escolar, seus conflitos e cotidianidade, não são totalmente absorvidos pelo estagiário. Ainda assim, as aulas de observação que precedem às regências são importantes momentos de reconhecimento do ambiente escolar, percebendo os problemas estruturais e de organização, bem como as qualidades e possíveis usos do espaço da escola.

O Estágio Supervisionado proporciona aos acadêmicos a aplicação dos conhecimentos relativos à sua área de estudos, atrelando informações da Didática com sua área específica de formação. Assim, é também um momento de treinar alternativas, usar os recursos e se reconhecer na profissão docente. Essa complexidade gera ansiedades e curiosidade, e tanto os estagiários, quanto os professores orientadores e supervisores, devem ter certa flexibilidade para melhor conduzir a experiência do estágio, uma vez que nem sempre aquilo que foi planejado efetivamente se constituirá na prática da sala de aula. É, portanto, um momento de crescimento e amadurecimento na formação do Licenciado em Geografia.

Considera-se, neste sentido, que o Estágio Supervisionado é parte essencial na formação dos professores e, que sem esta primeira experiência, a Licenciatura não se concretiza de fato como formação do docente. É no contexto 
do estágio que os alunos percebem a formação que escolheram, vivenciam aquilo que estão aprendendo teoricamente na universidade e se reconhecem (ou não) na profissão que decidiram seguir. A forma como o Estágio Supervisionado é organizado, pelo menos no âmbito do caso analisado, oferece aos acadêmicos condições de amadurecimento, pois todas as etapas são criteriosamente constituídas, e trabalha-se no sentido de progressão, primeiramente com o Ensino Fundamental e posteriormente com o Ensino Médio. Os alunos são acompanhados constantemente por professores preparados para tal atividade, havendo ainda um momento de devolutiva ao término da experiência. Assim, entende-se que o Estágio Supervisionado merece destaque e se constitui em ponto crucial na formação de Licenciados em Geografia, não podendo ser encarado como mero processo obrigatório na formação.

\section{REFERÊNCIAS}

ABREU, S. Formação do Professor de Geografia: construindo conhecimento, consolidando práticas. Aspectos da relação ensino-aprendizagem. In: ANDRES, J.; FRANCISCHET'T, M. N.; AGUIAR, W. G. (Orgs). Ensino de Geografia: abordagens sobre representações geocartográficas e formação do professor. Cascavel: EDUNIOESTE, 2012. p. 11-48.

CONSELHO DE ENSINO, PESQUISA E EXTENSÃO. Universidade Estadual do Oeste do Paraná (UNIOESTE). Regulamento do Estágio Supervisionado do curso de Geografia, do campus de Marechal Cândido Rondon. Resolução No 322/2011-CEPE, de 15 de dezembro de 2011. Disponível em: < http://www.unioeste.br/ servicos/arqvirtual/arquivos/3222011-CEPE.pdf $>$. Acesso em 02 Set. 2016.

PIMENTA, S. G.; LIMA, M. S. L. Estágio e docência: diferentes concepções. Revista Poíesis, Vol. 3, N. 3 e 4, p.524, 2005/2006. Disponível em: < http://www.cead.ufla. br/portal/wp-content/uploads/2013/10/Arquivo_referente_ao_Anexo_V_do_Edital_CEAD_06_2013.pdf $>$. Acesso em 15 Ago. 2016.

VLACH, V. R. F. Ensino de Geografia no início do século XXI: desafios e perspectivas. Disponível em: < http://observatoriogeograficoamericalatina.org.mx/ egal9/Teoriaymetodo/Teoricos/04.pdf>. Acesso em 15 Ago. 2016.

\section{Correspondência da autora:}

Luana Caroline Künast Polon e-mail: luanacaroline.geografia@gmail.com

Artigo recebido em: 19/01/2017

Revisado pelo autor em: 23/02/2018

Aceito para publicação em: 15/03/2018 